\title{
REPRESENTAÇÕES SOCIAIS E NARRATIVAS PUBLICITÁRIAS: orgulho de ser LGBT pela Skol
}

\author{
Gustavo Souza Santos ${ }^{1}$ \\ Jhon Lennon Ribeiro da Cunha ${ }^{2}$
}

\begin{abstract}
Resumo: A produção de narrativas sobre a realidade, os sujeitos, os objetos e a realidade dos sujeitos e objetos é substrato para discurso publicitário. Este se apropria de imagens populares para estabelecer ligações representativas enraizadas na sociedade, o que pode alimentá-la ou retroalimentá-la com suas próprias cosmovisões. A representação e a narrativa sobre o sujeito LGBT têm sido foco de estudos e exames, especialmente considerando o discurso publicitário. O objetivo do estudo foi analisara campanha \#RespeitoIsOn da marca Skol, considerando as dinâmicas de narrativa e representação LGBT. Para tanto, metodologicamente, desenvolveu-se um estudo de caso com aporte documental, tendo por corpus as peças da campanha questão por meio técnica de análise de conteúdo. O arcabouço teórico do estudo considerou Barthes (1977), Foucault (1988), Jodelet (2001), Moscovici (2007), Simões e Facchini (2009) e Seffner (2011) na associação entre narrativa publicitária, identidade de gênero e representações sociais.
\end{abstract}

Palavras-chave: LGBT. Representação sociais. Representatividade. Narrativas publicitárias.

\begin{abstract}
The production of narratives about the reality, the subjects, the objects and the reality of the subjects and objects is substrate for the advertising language. This is the case with popular images for establishing representative connections in your society, which can feed or feed your worldviews. A representation and a narrative on the subject LGBT has been the object of studies and examinations, especially considering the advertising speech. This study was published in the campaign \#RespeitoIsOn of Skol, considering narratives of LGBT narrative and representation. Methodologically, it was developed a case study with documental support considering the advertising campaign through content analysis. This paper considered thoretically Barthes (1977), Foucault (1988), Jodelet (2001), Moscovici (2007), Simões and Facchini (2009) and Seffner (2011) in promoting dialogue among advertising narrative, gender identity and social representation.
\end{abstract}

Keywords

LGBT. Social representations. Representativity. Advertising narratives.

\section{Introdução}

As narrativas, como são entendidas por Barthes (1977), são numerosas e acima de tudo compreendem uma variedade de gêneros distribuídos em diferentes substratos para que o homem conte suas histórias. Os indivíduos, dotados de tal capacidade, usam da narrativa em articulados meios de expressão, seja pela literatura, imagem ou sons para apresentar seu ponto de vista em relação ao que abstrai do universo. Todo sujeito possui suas próprias narrativas

\footnotetext{
${ }^{1}$ Doutorando em Desenvolvimento Social e mestre em Geografia pela Universidade Estadual de Montes Claros (Unimontes). Docente das Faculdades Integradas Pitágoras de Montes Claros (FIPMoc).

${ }^{2}$ Graduado em Comunicação Social - Publicidade e Propaganda pelas Faculdades Integradas Pitágoras de Montes Claros (FIPMoc).
} 
que se projetam como um deslocamento no espaço e no tempo, na apresentação de fatos que simbolizam refúgio na vida cotidiana.

Esse campo simbólico e imaterial serve de contexto para o discurso publicitário que, assim como Gastaldo (2013) diz, apropria-se de dizeres e imagens populares na intenção de estabelecer ligações representativas enraizadas na sociedade, o que muitas vezes alimenta uma função eminentemente conservadora.

Sendo a comunicação uma das formas de propagação dos saberes, em especial os saberes populares, a exemplo dos estereótipos (JODELET, 2002), entende-se que este trabalho busca pautar e compreender o modo como as imagens são geradas, o quão sintomático são os paralelos entre o que é normativo e transgressor, os papéis e governanças sobre os corpos dos indivíduos, e ditames das relações interpessoais.

Os LGBTs vivem experimentações (SEFFNER, 2010) - assim como qualquer indivíduo que fuja a norma heteronormativa - que os conferem afirmações de resistência aos modelos dominadores na sociedade, e essas experimentações geram sensações condenadas por polos majoritários, uma vez, que o ponto de partida das narrativas origina-se de uma cultura que é suficiente em si, obtém-se como resultado o rompimento com paradigmas normativos e abertura de espaço para novas concepções dos indivíduos, bem como o surgimento de próprios paradigmas.

Este estudo analisou a campanha \#RespeitoIsOn da marca Skol, considerando as dinâmicas de narrativa e representação LGBT. Empreendeu-se um estudo do tipo documental, tendo por corpus a peça principal de campanha, examinada a partir da técnica de análise de conteúdo.

\section{Narrativas para discutir publicidade}

Os primeiros estudos sobre a narratividade advêm da literatura, onde para Schmid (2010) os trabalhos críticos literários sugerem dois conceitos distintos de narratividade: clássica e estruturalista. Determinou-se o conceito clássico como possuidor de recursos linguísticos específicos para comunicação. Tais estudos sugerem que a natureza da narração está subjugada ao prisma (ponto de vista) de um narrador, ou seja, sugere dependência de uma autoridade mediadora para que as representações do mundo narrado façam sentido. É o que se para Friedemann (1910), representa a presença do narrador, sendo como uma maneira de alcançarmos o universo através de um ponto de vista, uma ideia já concebida. 
No que se refere ao modo estruturalista, Todorov (1969) distancia sua definição das características do discurso e se aproxima do que é narrado. É concebido que os estudos estruturalistas definem como narrativa os textos que possuem um espaço temporal onde acontece mudanças de estado dos eventos, do que está sendo narrado. Enquanto no conceito clássico o domínio verbal de comunicação descritiva e de relatos é o seu espaço, considerando apenas trabalhos que trazem consigo a figura do narrador, o estruturalismo consegue produzir textos líricos, cinemáticos e dramáticos, mesmo que exclua aqueles que não possuem estrutura temporal de mudanças de estado.

\footnotetext{
Uma narrativa "ideal" começa com uma situação estável afetada por alguma força ou poder. Há como resultado um estado de desequilíbrio; com uma nova força em direção oposta, o equilíbrio é restabelecido; ou seja, o segundo equilíbrio é similar ao primeiro, mas os dois nunca serão idênticos. (TODOROV, 1977; p.111 [tradução nossa])
}

Por essas abordagens acerca das narrativas, Bello (2001), entende que fica evidente a presença de duas entidades que constituem as narrativas, a figura do narrador, responsável por alocar os acontecimentos e estabelecer uma lógica entre os eventos, e a própria história composta pelos objetos e eventos em constante mudança de um estado a outro.

Ainda para Bello (2001), a narração é uma forma de assegurar ordem significado e constatação das experiências do homem, pois o homem com produtor de cultura e vivido explorador do âmbito social terreno, vê na narratividade uma maneira singular para relatar sua história e simbolismos, sejam representações textuais, iconográficas artísticas. Portanto, a narratividade não pode ser vista apenas como uma modalidade literária, sendo que vai de encontro ao que se interpreta e vivência nas experiências.

\section{Apelo e consumo, uma narrativa publicitária}

As narrativas publicitárias estão inseridas em uma lógica de consumo e trocas de bens/serviços, sendo que o seu discurso percorre um caminho estreito do real e ao imaginário num sistema midiático, esclarecendo um fato e um atributo. O sistema midiático em poder do território simbólico e material, persegue os indivíduos na busca por interação e, vez ou outra, esses discursos assumem o papel de "metamercadoria", mensagens, mas também produtos. (CARRASCOZA, 2014) 
Para Gastaldo (2013), dentre os vários gêneros discursivos, - “jornalismo, dramaturgia, humorístico, lúdico, infantil, etc.” - a publicidade por possuir elementos próprios, pode ser caracterizada como um gênero discursivo. Algumas peculiaridades como aponta o autor, são elementares nas suas construções. O discurso publicitário é uma defesa pública, no entanto obedece a interesses privados, pois muito diferente dos outros, o seu financiador assina o nome em baixo do seu anúncio, além de não com rigor como o jornalismo possuir obrigatoriedade e fidelidade aos fatos, ou, transmissão de informação.

No bojo das narrativas publicitárias, como é observado por Carrascoza (2014), há valores implícitos e explícitos do contexto histórico que foi enunciada. Os anúncios são compostos por dizeres verbais e visuais relativos aos produtos/serviços, abrem margem para conflitos de ideias e investem no imaginário coletivo. Esses conflitos estão pautados nos dizeres e não dizeres do discurso. Muito pelo que já foi dito, e uma impossibilidade natural de não o repetir, e pela adoção de terminado dito em detrimento de outro, sendo que sua fala inaudível tenha motivos específicos. Um motivo simplório seria por não promoverem tanto a mercadoria e seus conceitos.

Dependendo do enquadramento, o discurso publicitário é um tanto ambíguo, pois se no enquadro mercadológico é apenas uma peça complementar nas estratégias de determinada campanha, parte de um maquinário de distribuição, fornecedores, clientes, trocas, o mesmo discurso assume o caráter antropológico, uma vez, que performa uma lógica simbólica da sociedade. Os elementos culturais são reapresentados sob a ótica do mercado, sendo assim uma fonte do imaginário social. Então o discurso publicitário não é uma crônica de costumes, e suas narrativas refletem lógicas que são inerentes ao sistema capitalista. (GASTALDO, 2013)

\section{Representações sociais, o senso comum sobre LGBTs}

Vivemos num universo de construção e desconstruções de imagens adotando algumas em detrimento de outras e, acrescentando algo a elas. O processo de representação categoriza estímulos que recebemos do meio, até mesmos os estímulos físicos. Pensar em representações é fundamentalmente classificar, denotar, buscar uma categoria para reconhecer o contato com o estranho. Enunciados que nos parecem estranhos e são perturbadores, possuem algo a ensinar e mostram como as pessoas pensam e no que eles pensam. 


\begin{abstract}
As representações sociais constituem uma espécie de fotossíntese cognitiva: metabolizam a luz que o mundo joga sobre nós sob a forma de novidades que nos iluminam (ou ofuscam) transformando-a em energia. Esta se incorpora ao nosso pensar/perceber este mundo, e a devolvemos a ele como entendimento mas também como juízos, definições, classificações. Como na planta, esta energia nos colore, nos singulariza diante dos demais. Como na planta, ela significa intensas trocas e mecanismos complexos que, constituindo eles mesmos um ciclo, contribuem para o ciclo da renovação da vida. [...] minha convicção [é] que nesta química reside uma possibilidade de descoberta da pedra filosofal para o trabalho de construção de novas sensibilidades ao meio ambiente. Ou seja, é nela que residem nossas chances de transformar ou, quando menos, de entender as dificuldades para a transformação do pensamento social. (MOSCOVICI, 2007, p.138)
\end{abstract}

Jodelet (2001, p.22), oferece um entendimento coerente sobre representações sociais, onde: "As representações sociais são uma forma de conhecimento socialmente elaborado e compartilhado, com um objetivo prático, e que contribui para a construção de uma realidade comum a um conjunto social. " Ainda lembra que a representação social deve abranger as relações no que diz respeito aos elementos afetivos, sociais e mentais ao lado cognitivo da comunicação e linguagem, atenta as relações sociais que afetam as representações materiais, sociais e ideias naquilo que intervirem.

Em se tratando desses "elementos", Gastaldo (2013) explica que a publicidade na tentativa de despertar no público-alvo o desejo de compra, utiliza-se de "representações" desse público a fim da contextualização do grupo nas campanhas pelos apelos. É uma "imagem" dos valores, comportamentos, gostos que são atribuídos pelo publicitário através do discurso publicitário, necessariamente uma imagem que fica no lugar do público.

No processo de edificação das condutas em representações sociais, conseguimos apontar as interferências que a comunicação exerce na opinião, atitude e estereótipos. Dotada do conhecimento sobre sua audiência, a comunicação possui propriedades estruturais diferentes, que são à difusão, à propagação e à propaganda. "A difusão é relacionada com a formação das opiniões; à propagação com a formação de atitudes e a propaganda com a dos estereótipos. " (JODELET, 2001, p. 30)

A utilização de estereótipos é constante em narrativas publicitárias. Como Carrascoza (2004) observa, os estereótipos são enunciados, imagens já compartilhadas pelo público, não exigem esforço para serem compreendidas. Os personagens desenvolvidos nesse tipo de narrativa são planos, não tem profundidade, dessa forma a comunicação ganha tempo de leitura pois mesmo aqueles que não estão dentro do universo pretendido possuem repertório para decodificar a mensagem, pois os enunciados fazem parte de seus repertórios. 
Nicolau (2011) contribui ao nível linguístico da mensagem, para o argumento de que um "bom" texto publicitário é aquele que minimamente, ou, em uma palavra, consegue condensar em si uma retórica rica que liberta imagens que por sua vez são a concretização simbólica de temas oriundos da sociedade. $\mathrm{O}$ autor ainda monstra que os critérios da linguagem publicitária são os mesmos da poesia: "figuras de retórica, metáforas, jogos de palavras, todos esses signos ancestrais que são signos "duplos", dilatam a linguagem em direção a significados latentes e dão assim ao homem que os recebe o próprio poder de uma experiência de totalidade."

\section{De subcultura a cultura, LGBTs numa perspectiva sobre público e consumo}

Se para Boone e Kurtz (2012, p.52) a cultura é "um conjunto de valores, crenças, preferências e gostos passados de uma geração para outra", fala-se também de valores materiais, e ao observar os valores, hábitos e costumes que definem a maneira pela qual percebemo-nos nos produtos e serviços, nota-se que são aprendizados compartilhados dentro de um grupo social. A exemplo das regionalidades, determinado costume pode ser visto como normal para uma região e reprovado por outra.

Porém, Vila Nova (1999) ressaltou que de modo que as subculturas não são um conjunto simples de pessoas, sendo essas pessoas integrantes e não subculturas propriamente, então regiões não seriam necessariamente subculturas. Mesmo que reconheça que as regiões e suas populações possuam características culturais próprias. $\mathrm{O}$ autor revela ainda que vem sendo cada vez menos frequente esse tipo de subcultura devido à expansão dos meios de comunicação em massa. Subcultura coexiste com a cultura geral, mesmo que diferente do todo, no entanto dependente.

Segundo sua observação, Paixão (2012) diz que deve-se levar em consideração que as mudanças nas culturas são frequentes e variantes de país para país, e é modificada pela diversidade da população. A subcultura é um segmento dentro da cultura, são valores e padrões comumente compartilhados, identificados em alguns aspectos como a idade, religião, etnia, nível de renda, nacionalidade, sexo, tipo de família, ocupação. Esse tipo de classificação permite que a empresa alcance com maior assertividade um grupo específico, e mostra que um indivíduo pode pertencer a várias subculturas. 
A exemplo da expansão do significado de pertencimento, a subcultura LGBT é uma porta para novos mercados e em expansão no Brasil. Sua distribuição nacional concentra-se entre São Paulo e Rio de Janeiro, sendo que outras cidades tais como Salvado, Porto Alegre e Fortaleza também prosperam em relação aos mercados direcionados a LGBTs. As investigações foram feitas em 2003 pelo Mix Brasil e L2. Apontam por exemplo o auto grau de escolaridade, média salarial $15 \%$ acima dos demais trabalhadores, e disposição para gastos com entretenimento, no entanto as mensagens direcionadas a esse público são escassas. (ASSUMPÇÃO, 2004)

O processo de construção das identidades, ocupação de espaços por LGBTs, é mostrado por Pollak (2015) a afirmação pública que chega até as organizações econômicas, políticas e espaciais. Para tanto, nos Estados Unidos teve-se um exemplo de grupos segregados nos grandes centros que foram formando guetos que são constituídos de grupos marginalizados que acabam desenvolvendo políticas próprias de relacionamento de trocas, estabelecem uma vida relativamente autônoma.

Quando se retoma aos aspectos característicos da subcultura LGBT em termos mercadológicos, algumas constatações são destaque. Seus integrantes são jovens, $63 \%$ tem no máximo 30 anos, e $21 \%$ de 30 a 40 o que totaliza em $84 \%$ de pessoas com menos de 40 anos. Sobre o nível escolar, se equiparam a países de primeiro mundo, 58\% possuem ensino superior. Em relação a atividades voltadas para lazer, entretenimento cultural, se comparados com heterossexuais sobre ir ao teatro, $60 \%$ vão com frequência frente aos $40 \%$ dos héteros. $89 \%$ vão regularmente ao teatro, $73 \%$ fazem viagens constantes o que é expressivo até para países desenvolvidos. (ASSUMPÇÃO, 2004)

Pullak (2015) ressalta com base nos teóricos Semenik \& Bamossy, não existe um modo único de ser gay, portanto não necessariamente um modo único de compra. Porém, entende que a maneira correta de tratamento seria como uma subcultura de consumo além de questionar a expressão "mercado gay”, que seria mais corrente. É como Assumpção (2004) aponta, as marcas que se direcionam para esses públicos, serão consideradas vanguardistas e promotoras de integração social. 


\section{Representação LGBT e orgulho de ser pela Skol}

As experiências vividas na feminilidade e masculinidade são compreendidas de nuances que permiti vivências variadas na existência do ser humano. No entanto, essas vivências em uma cultura heteronormativa dominante, há uma dificuldade em reconhecê-las. Ainda que notadamente perceba-se que o universo social é composto pela diversidade de pensamentos, pessoas, cultura, é inegável que certas determinadas sejam consideradas mais "corretas" que outras (LINS; MACHADO; ESCOURA, 2016). Já dizia Foucault (1988) que pela burguesia vitoriana a sexualidade é confiscada para dentro de casa, a instituição familiar agora a detêm. Nisso surgem as censuras, vindas de um lar matrimonial em que os resquícios da sexualidade de certo existem apenas no quarto dos protagonistas desse matrimônio, impõem-se como modelo e reina-se a norma.

A despeito da variedade das condutas dos sujeitos, os modelos que ainda seguem-se perpetuando na sociedade tendem a reprimir o que inflige as regras dos grupos dominantes. Repressão é na mesma medida a negação da existência, condenação ao desaparecimento, desarmamento do diálogo, negação FOUCAULT (1988). Lógica que pode explicar trágico contraste entre o fato de o Brasil ocupar a posição de número um em mortes de LGBTs, mas que, por outro lado, abriga a maior Parada do Orgulho LGBT do mundo (LINS; MACHADO; ESCOURA, 2016). Se por um lado existe a intolerância, há um outro que serve uma estrutura de poderes. Pela fala de Foucault (1988) em crítica às sociedades burguesas, via-se as concessões acontecerem na surdina; gestos, desejos, palavras, poderiam acontecer desde que em locais escondidos.

Os enunciados para Foucault (1988) de opressão e pregação reforçam-se numa relação recíproca. Falar sobre o poder pela perspectiva da repressão é ir de encontro a uma economia, de todos os interesses que a sustentam. Esse modelo de repressão sexual faz ressalvas quando o estado percebe que sob um projeto de riqueza e crescimento de uma nação, é necessário por vias do controle do sexo povoar uma nação e, fazer com que a sociedade entenda que não será possível senão por via dele, ao passo que também se regule o seu uso. O discurso sobre o sexo poderia ser acessado somente por necessidades precisas, uma urgência econômica, utilidade política, mas sempre atentando para a codificação das condutas de tratamento. 
Talvez seja nessas exceções, na redução da sexualidade a sua valorização como o segredo ${ }^{3}$, é que alimenta-se um discurso de recomendação, ideais, e propagação das moralidades em relação ao sexo. Como pôde-se perceber, o discurso sobre o sexo abarca uma camada econômica, administrativa social. Traz para o cotidiano as representações do que seria o bom uso da sexualidade, há de certo uma doutrinação através de preceitos que vem de instituições familiares, religiosas, e por que não financeiras. Uma ilustração dessa situação, é quando Jodelet (2002) citou que no surgimento do HIV, a população assustada por um controle dessa narrativa que até então não tinha um domínio, fosse associada a uma prática sexual entre casais homossexuais, muito antes de um aval científico, tem-se então os versos da sexualidade e das representações sociais a cerca de um fato, o conhecimento elaborado pelo senso comum. No sentido das representações sociais de Gastaldo (2013), a publicidade acessa acervos culturais do imaginário simbólico do público segundo uma lógica de mercado. As lógicas que dão significados as produções publicitárias e seu discurso, atendem não somente uma "crônica dos costumes", ela é pautada em uma conjuntura econômica/simbólica, suas narrativas tanto atendem um discurso privado, que por momentos alimentam certo conservadorismo, tanto quanto visam as práticas do sistema capitalista. Acontece a busca pelo "efeito de compra", o discurso publicitário abandona lógicas de persuasão racionalizantes e percorre o caminho da “identificação". Oferta ao público uma representação que seja "próximo de sua realidade" num ritual de envolvimento e, geralmente são nessas idealizações da realidade é que as representações falam, pois terminam por valorizar categorias hegemônicas em detrimento de outras.

LGBT é uma sigla que ainda está em construção, pois é resultado de afirmativas de identidades fluidas, transitórias. A sigla abrange identidades afetivas e identidades de gênero, se primeira está relacionada as relações que compartilhadas no campo sexual, a segunda trata do reconhecimento do corpo individual na sociedade de acordo com suas personalidades e pertencimentos. São lésbicas, gays, bissexuais e transexuais, sendo que ainda há um reconhecimento das pessoas travestis e transgêneros, como (I) intersexuais é (Q) queers. (SIMÕES; FACCHINI, 2009) As representações a seguir, narram os dilemas vividos pela comunidade LGBT tendo como plano de fundo o dia internacional do orgulho de ser LGBT

\footnotetext{
${ }^{3} \mathrm{O}$ que é próprio das sociedades modernas não é o terem condenado o sexo a permanecer na obscuridade, mas sim o terem-se devotado a falar dele sempre, valorizando-o como segredo. (FOUCAULT, 1988)
} 
em referência a resistência conhecida pelo evento de Stonewall nos Estados Unidos frente a repressão da sociedade e da política da marginalização da homossexualidade.

A Skol em campanha para internet diz que precisa tratar de uma questão importante para a sociedade, é o dia Internacional do Orgulho LGBT ${ }^{4}$. Sobre assinatura, "\#RespitoIsON", a campanha inicia com uma sirene estridente, o enquadramento da cena é sequencial do asfalto até focar-se na caminhada solitária da personagem numa noite escura em cenário urbano. A personagem, um jovem, está vestida de maneira não convencional, branco, roupas frouxas, maquiagem ao redor dos olhos, cabelos tingidos de rosa platinado, pulseiras, corpo tatuado e piercings, um pequeno retrato underground da vida urbana (figura 1).

Uma caminhada solitária que ao longo dos tempos demonstra ser penosa para personagem, pois vez ou outra a sua expressão é de apreensão, quase como se algo fosse acontecer a qualquer momento, até que acontece. Ele começa a despertar a atenção de outros pedestres nesse longo caminho de extensões indefinidas, as pessoas trocam olhares com ele, algumas chegam a esbarrar-se, deixando-o ainda mais apreensivo.

A narrativa muda quando uma personagem que passava por ele volta e pega a sua mão, os dois se olham e continuam a andar de mãos dadas, nisso mais pessoas a sua frente e que vão se esbarrando começam a se juntar a eles e, aquilo que era uma caminhada solitária e silenciosa, se transforma em uma marcha de pessoas com backgrounds. Sinalizadores de fumaça são acesos, e a caminhada se segue até o amanhecer, a multidão a frente da marcha está enfileirada de mãos dadas, as cores dos sinalizadores desenham a bandeira LGBT no ar, toda tensão inicial da campanha fica para trás assim com os olhares de desdém, quando finalmente a assinatura aparece acompanhada da única fala do comercial além da sonoplastia.

${ }^{4}$ Clube de Criação - Skol. Disponível em: < http://www.clubedecriacao.com.br/ultimas/respeito-is-on/ > Acessado em 16 de nov. 2016. 
Figura 1 - Cena de abertura da campanha

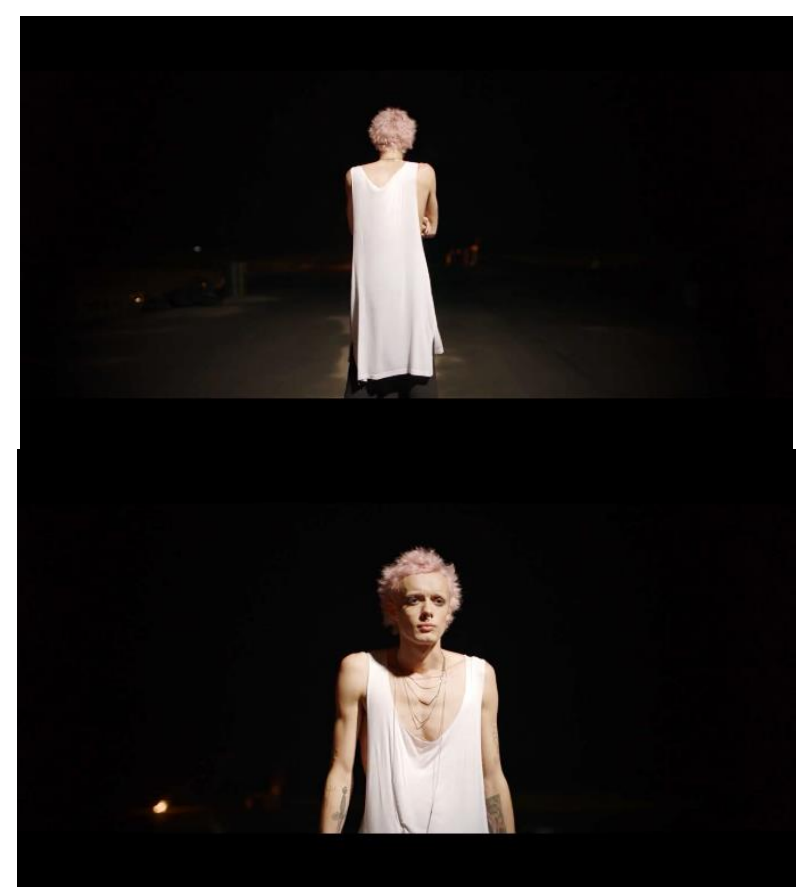

Fonte: peça de campanha Skol.

A campanha foi veiculada nas mídias digitais da empresa no dia 28 de junho de 2016, dia Internacional do Orgulho LGBT, dia histórico para comunidade num ato contra a intolerância em um bar conhecido como "Stonewall Inn", foi nesse então que lésbicas, gays, bissexuais, trasvestis, drag queens se uniram em resistência contra a repressão e violência que eram submetidos (RIBEIRO; 2011). Em 1969 era proibida a venda de bebida alcoólica a LGBTs em Nova York, muitos casos de prisão envolvendo os consumidores e donos de bares eram frequentes, a posição agressiva da polícia ia de encontro a passividade das pessoas durante as ações policiais ${ }^{5}$. Esse momento de passividade e opressão justifica a então solitária sirene sobre o andar solitário se silenciosa da personagem.

O modo de narrar nesse anúncio Carrascozza (2004), é uma junção do narrador em primeira pessoa, onde a personagem principal está inserida na cena de maneira que conduz a narrativa sob sua subjetividade, ou seja, o anúncio é compreendido segundo sua perspectiva, também no segundo modo de narrar, em terceira pessoa, quando os enquadramentos e composições de cena também falam. Quando observado o quadro abaixo, percebe-se que a leitura do anúncio é sobre a perspectiva da personagem, a senhora (figura 2) encara-lhe na altura dos olhos, aparentemente preocupada com a personagem central. Os contrastes servem de ligação dos

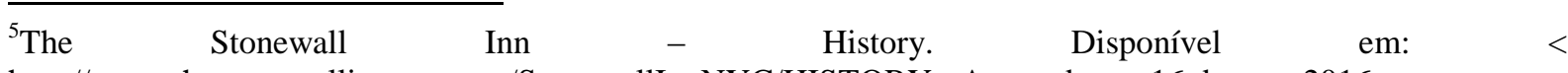
http://www.thestonewallinnnyc.com/StonewallInnNYC/HISTORY> Acessado em 16 de nov. 2016. 
quadros, situações calmas versam com momentos tensos, bem quando uma das personagens com megafone, aparência conservadora semelhante a figuras religiosas, grita e aponta agressivamente.

Figura 2 - Cena da senhora na campanha
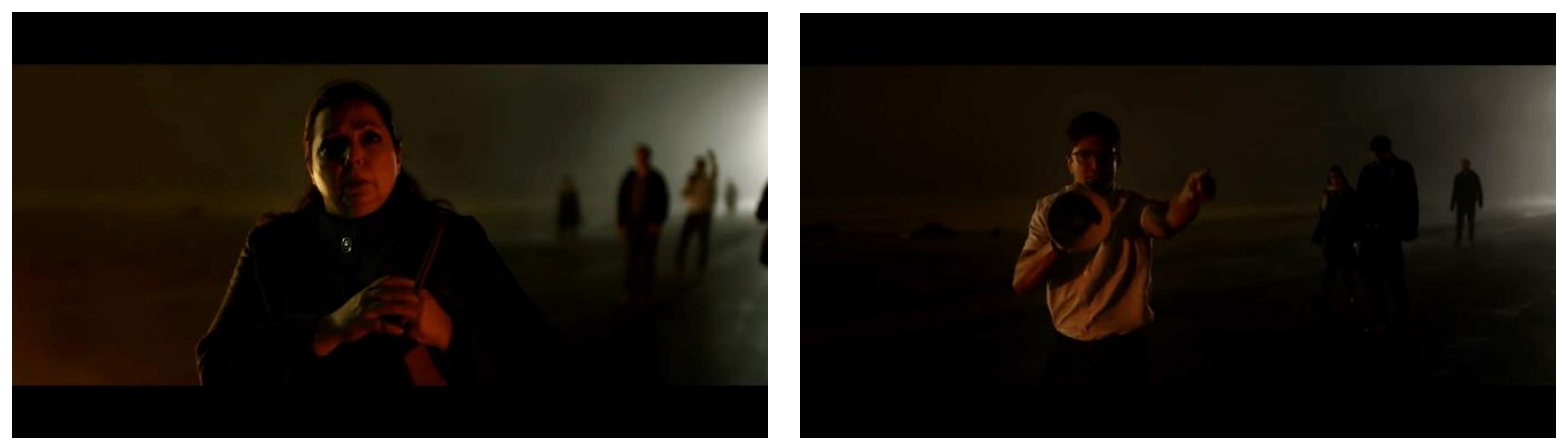

Fonte: peça de campanha Skol.

Quando se aprofunda nas tramas da personagem principal, alguns detalhamentos da sua personalidade são representados no que pode se chamar de metáfora narrativa. Uma personagem LGBT, logo não possui as mesmas referências que uma sociedade baseada em valores heteronormativos têm, ainda mais diante da opressão que sofrem por serem uma "minoria". Bem como observa Seffner (2011), as experiências LGBT vivem um dilema constante, pois suas experiências são por vezes sujeitadas a experiência heteronormativa, quando na verdade isso significa um meio de estabelecer outras os de conduta predatórios, onde entre certos e errados colaboram para manutenção de opressões dentre LGBTs. Essa experiência heterossexual não faz parte da narrativa da personagem como visto no primeiro e segundo quadro, o quadro do casal desfocado (figura 3) pela visão subjetiva da personagem em continuidade com o segundo que contrasta a invisibilidade que outras experiências de ser, o casal apenas esbarra na personagem e pouco nota-se de sua presença. 
Figura 3 - Cena do casal na campanha

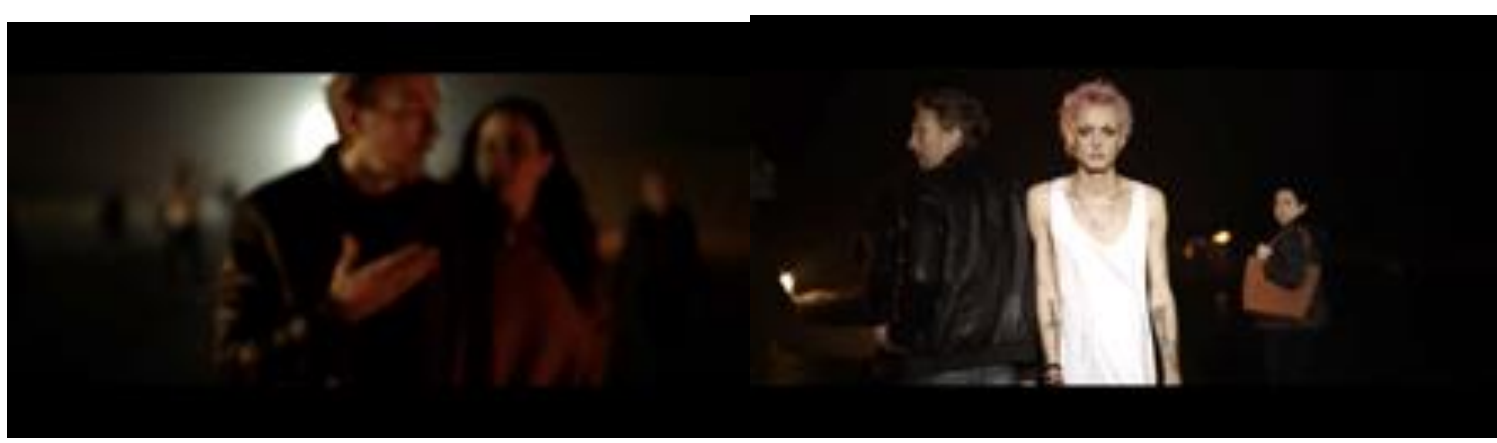

Fonte: peça de campanha Skol.

Em anúncios narrativos Carrascozza (2004), o uso de figuras serve para suscitar a realidade como tentativa de representar o mundo, seja pelas palavras, expressões existentes no mundo real, ou, fictício. Um caso que ocorreu em 14 de novembro de 2010 na Av. Paulista em São Paulo $^{6}$ (figura 4) que serviu de denúncia da homofobia presente no Brasil e na sociedade como um todo, teve sua versão no anúncio da Skol. Na ocasião do dia 14, três jovens voltavam de uma casa noturna quando foram surpreendidos por grupo de adolescentes acompanhados por um maior de idade em que um dos adolescentes portando lâmpadas fluorescentes desfere golpes na cabeça de um dos três jovens que voltavam da festa sob alegações de que esse seria homossexual. A figura no anúncio faz uma referência ao acontecimento, quando a personagem continua a andar e logo a frente aparece essa figura intimidadora de um homem que traz consigo um objeto luminoso fluorescente, seus gestos demonstram frieza e são fixos na personagem (figura 4).

\footnotetext{
${ }^{6}$ Homofobia - Globo G1 SP. Disponível em: < http://g1.globo.com/sao-paulo/noticia/2010/12/pensei-que-iamorrer-diz-jovem-agredido-com-lampada-na-paulista.html > Acessado em 21 de nov. 2016.
} 
Figura 4 - Referência à lâmpada
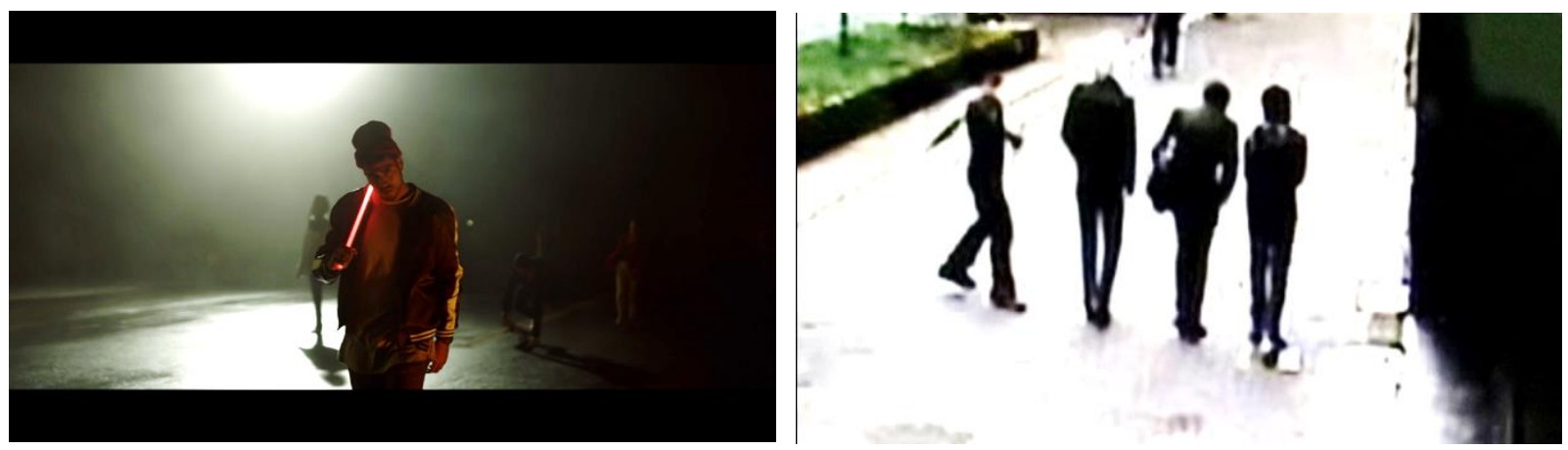

Fonte: peça de campanha Skol.

Uma das grandes dificuldades de tipificação, categorização da agressão a LGBTs está na falta de aparato do estado para que seja possível fazer os recortes sociais necessários da situação da população LGBT, pois existem violências direcionadas a gays, lésbicas e bissexuais que em uma pessoa trans é agravado por outros fatores. Gays são atacados por serem afeminados, lésbicas são violentados pela desculpa machista de que são o que são pela feita de "um homem", travestis, transsexuais e transgêneros são vítimas de preconceito ao tentarem acessar serviços públicos e frequentar espaços além do fato de estarem sujeitos a violências físicas com maior incidência como já apresentado. A violência que não é sentida por parte hegemônica da sociedade heteronormativa, que não têm tipos de opressões violentas específicos e endereçados como os sofridos por LGBTs, têm dificuldade de reconhecer essa necessidade de criminalização da homofobia, transfobia, leis de casamento igualitário, pois são privilégios atribuídos a sua conduta "respeitável” e que por isso merecem resguardo.

O processo de ancoragem por Moscovici (2007) que permite entender o processo de nomear, classificar, estranhamento, permite-nos perceber como se classificou as condutas do sujeito LGBTs, que foi sujeitado a pareceres médicos, escrito sobre perspectivas psiquiátricas, tratadas como pecado. Essas práticas que fizeram parte da propagação de ideias de discriminação e preconceitos, recaem sobre a sociedade a séculos. Ao edificar a figura LGBT, limita-se não somente a uma vivência tolerável, mas excluí qualquer possibilidade de uma nova experiência dos corpos seja vivida. Se não consegue dar nome a algo, explanar sobre o mesmo, esse corpo logo não existe, ou, se não existe a representação da população e suas 
vivências proporcionalmente tais como as experiências reais, fatos, sua história também não existe.

Bento (2011) diz que conceito produz unidade e não ao contrário, a unidade não produz um conceito, o autor fala sobre a ficção que existe dentro dos conceitos para explicar que o ato de reconhecimento dos corpos (mulher, gays, transexuais) partem de um projeto social "existoso" que orienta o olhar. Enquanto mediador no processo de criação publicitária, os emissores apresentam e representam conceitos, mas será essa a unidade justificável a um grupo? Os modos de narrar são suficientes para atender suas demandas identitárias? As histórias que contam sobre LGBTs podem ser em certa medida verdadeiras e ao mesmo tempo serem incompletas, pois se há várias maneiras de viver a masculinidade ou feminilidade, também a várias maneiras de ser LGBT e, inclusive a negação de identidades como forma de construção individual de narrativas.

\section{Ecos da luta LGBT sob uma narrativa otimista}

No Brasil a internet é acessada por 59\% da população, pelo relatório da Freedom House de $2016^{7}$, a internet deixou de ser classificada livre para parcialmente livre, isso devido a ações de bloqueio de aplicativos, sites, pela justiça federal. Some-se ainda o controle da distribuição de internet por grandes corporações, qualidade questionável e preços praticados, e tentativas de modificação do Marco Civil da Internet que é considerado um dos mais progressistas ${ }^{8}$. Por outro lado, vivemos uma configuração da estrutura da mídia no Brasil que propícia a “concentração dos meios de comunicação de massa". Marinoni (2015) analisou as dificuldades de democratização da mídia no Brasil, segundo representação de desigualdades do capital monopolista. Hoje no Brasil, 97\% afirma ver televisão, e nesse campo de produção ideológica da indústria cultural, observou que existem grupos que dominam de maneira direta e sob lógica "vertical da programação", as redes, a mídia brasileira.

Em linhas gerais, esse monopólio sobre a mídia no Brasil constrói barreiras para livre distribuição e diversidade de ideias e pluralidade de pensamento. Além de irem contra a constituição que regula a radiodifusão no Brasil, esses controles exercidos pelos grandes

\footnotetext{
${ }^{7}$ Freedom House. Disponível em: < https://freedomhouse.org/report/freedom-net/2016/brazil > Acessado em 22 de nov. 2016.

${ }^{8}$ Converge Comunicação - Teletime. Disponível em: < http://convergecom.com.br/teletime/16/11/2016/brasildeixou-de-ter-internet-livre-diz-relatorio/ > Acessado em 22 de nov. 2016.
} 
grupos de mídia representam certo conservadorismo e padronização do mercado dificultando a entrada de competidores, onde afeta diretamente os produtos produzidos por esses grupos e indiretamente serve de critério para veiculação publicitária. Então, embora a internet seja um meio prático, ela ainda não chega em grande parte dos lares brasileiros, e a TV ainda meio de comunicação mais consumido e com maior participação publicitária, 67,5\% segundo InterMeios, mais ainda é ligada a pequenos grupos que dominam o mercado.

No que chama da vertical e horizontal, Mendonça (2007) apresenta a mediação que acontece na comunicação através da mídia, onde as vivências das minorias (horizontal) é subjugada a vertical (conservadora) espaço da "heterodeterminação" e "homogenização". Restou à horizontal as mídias secundárias como substrato para expressar seu corpo e suas experiências na pintura, fotografia por exemplo, teria que ocupar espaço na vertical midiática (massiva) para se comunicar a longo alcance. As lutas das minorias são cotidianas, uma vez conquistado determinado espaço esse será palco pra modificações constantes. Não é difícil ver nas mídias de massa a intermediação que coloca as minorias em posições estáticas, representações que não possuem camadas ou projeções menos óbvias.

Figura 5 - Cena da campanha

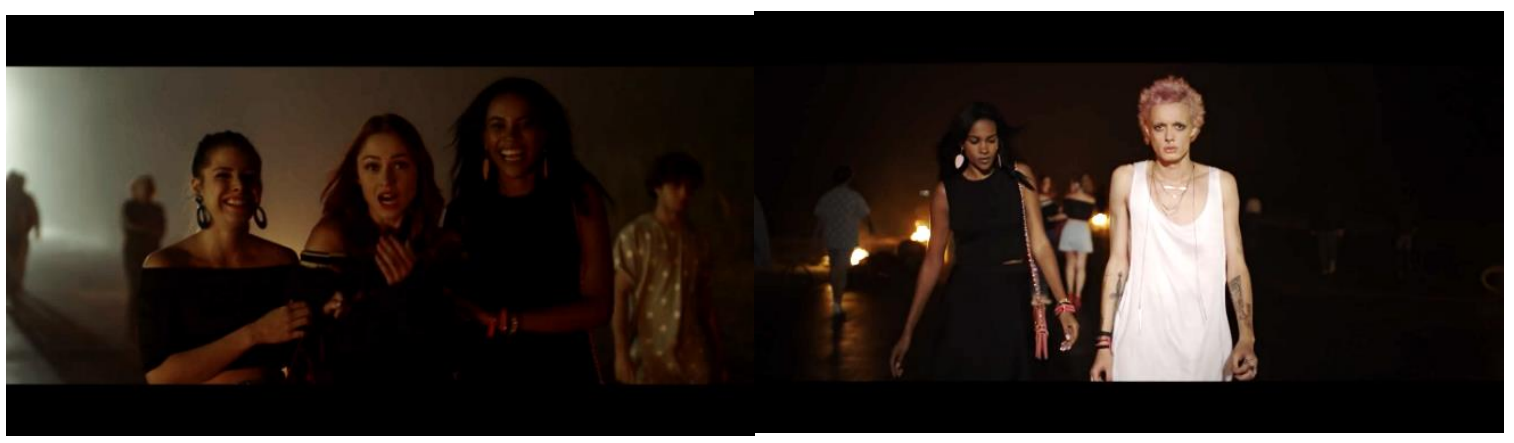

Fonte: peça de campanha Skol.

Nesse momento do anúncio retratado acima, tem-se a retomada do significado de Stonewall, as pessoas estavam em busca de reconhecimento de seus horizontes, clamavam por uma visão honesta de seus valores. (RIBEIRO, 2011). Se por um lado temos uma personagem que passivamente caminha a mercê de julgamentos (figura 5), em outra ponta uma outra personagem percebe que ela também pode ser oprimida e opressora ao mesmo tempo (figura 30). Quando a jovem do trio de amigas se conscientiza da situação que está vivendo, percebe que também precisa se alinhar as causas do movimento LGBT, o anúncio mostra então um 
retrato positivo da comunidade e dos personagens que por várias vezes são estereotipados e vítimas de um sistema de auto repressão.

Uma continuidade a mensagem de diversidade, a Skol foi uma das grandes apoiadoras da Parada do Orgulho LGBT de 2016 em São Paulo ${ }^{9}$, durante o evento foram vendidos produtos da marca, além de ter uma trio elétrico com artistas em continuidade com a campanha. Vemos a lógica da narrativa transmídia que Jenkins (2006) descreveu como o caminho da mensagem em meios, pois além de estar na internet o conceito consegue viajar para outros espaços ${ }^{10}$ sem que seja necessário o acesso em sequência, no entanto percebe-se que caso a marca não tive modificado seu posicionamento perante o público, a aceitação as suas propostas seria cautelosa, uma vez, que o mercado de bebidas tem um longo histórico de anúncios que objetificam mulheres. O anúncio concentrou uma variedade de personagens que justificassem a pluralidade da comunidade LGBT, no entanto esse sucesso que o case teve pode ser atribuído as outras frentes que a marca tomou.

Assim como a Avon, o direcionamento das campanhas da Skol seguem estratégias parecidas, suas ações são na maioria voltadas para internet e apoio a eventos, os conteúdos que a marca cria vão pros canais digitais (segue algumas das reproduções de suas redes sociais no dia da campanha abaixo), onde ainda esbarra-se na mesma problemática das marcas que se posicionam pró-diversidade, os corpos que elas buscam representar não são vistos pela grande maioria, os motivos podem ser vários, dentre a padronização da $\mathrm{TV}$, definição de públicoalvo, ou o risco que seria menor para uma campanha veiculada na internet por ser mídia secundária. O fato é que as mídias secundárias (figura 6) estão servindo de espaço para expressão de ideias mais progressistas, mas não muito distante essa falta representatividade vai ser sentida nos meios tradicionais.

Figura 6 - Peças auxiliares de campanha

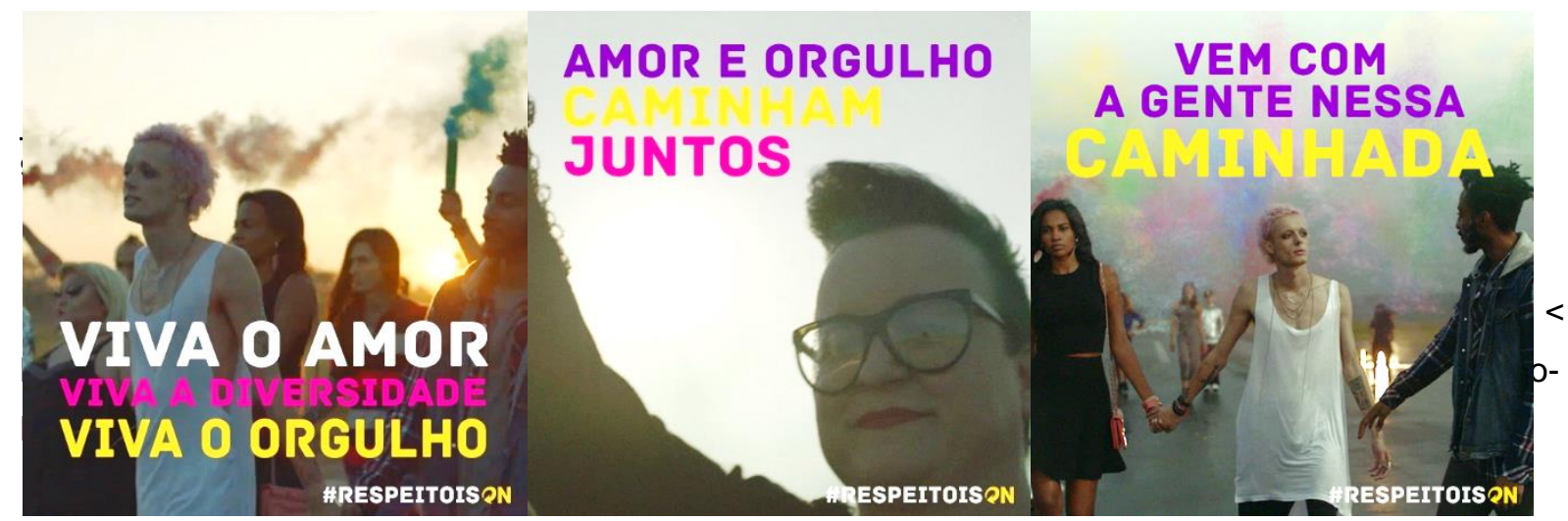


É de se reconhecer que essa mudança está associada a lutas dos LGBTs que contribuem para abertura do diálogo, como Simões \& Facchini (2009) observam, as iniciativas de grupos dos anos 80 como as do Grupo Gay da Bahia que vem denunciando a violência sofrida por LGBTs ao estado e a sociedade. De certo que a comunicação em publicidade também tenha evoluído, mas suas ações são análogas as demandas da sociedade. As narrativas no que Carrascoza (2014) observou, que criam o universo ficcional e simbólico de uma marca, valem-se de uma aliança com simbolismo de ordem racional, motivações que estão além dos produtos, mas que aos seus objetivos servem.

Ao decorrer das cenas, ocorre que um subtexto é contado pela passagem da noite para o dia (figura 7). Enquanto a personagem central estava caminhando sozinha os tempos eram de escuridão, a partir do momento que encontra apoio de outras pessoas as linhas que vão se formando a frente são mais claras, é a redenção do anúncio. As pessoas começam a se organizar, unirem suas diferenças. Laclau (1990 apud Hall, 2002) no seu conceito de deslocamento entendeu que a sociedade não está subjugada a um centro, princípio articulador ou organizador, que seu centro não é deslocado até outro, mas até uma pluralidade de centros, essa sociedade moderna tardia é classificada pela diferença. Entre divisões e antagonismos, como o autor argumenta que a sociedade de diferenças perpassa, vemos que no anúncio a sociedade articula-se de diferentes modos, etnias, raças, idade, reafirmando a pluralidade dos centros, elas buscam um mesmo objetivo mais suas identidades permanecem abertas (figura 7).

Figura 7 - Transição das cenas

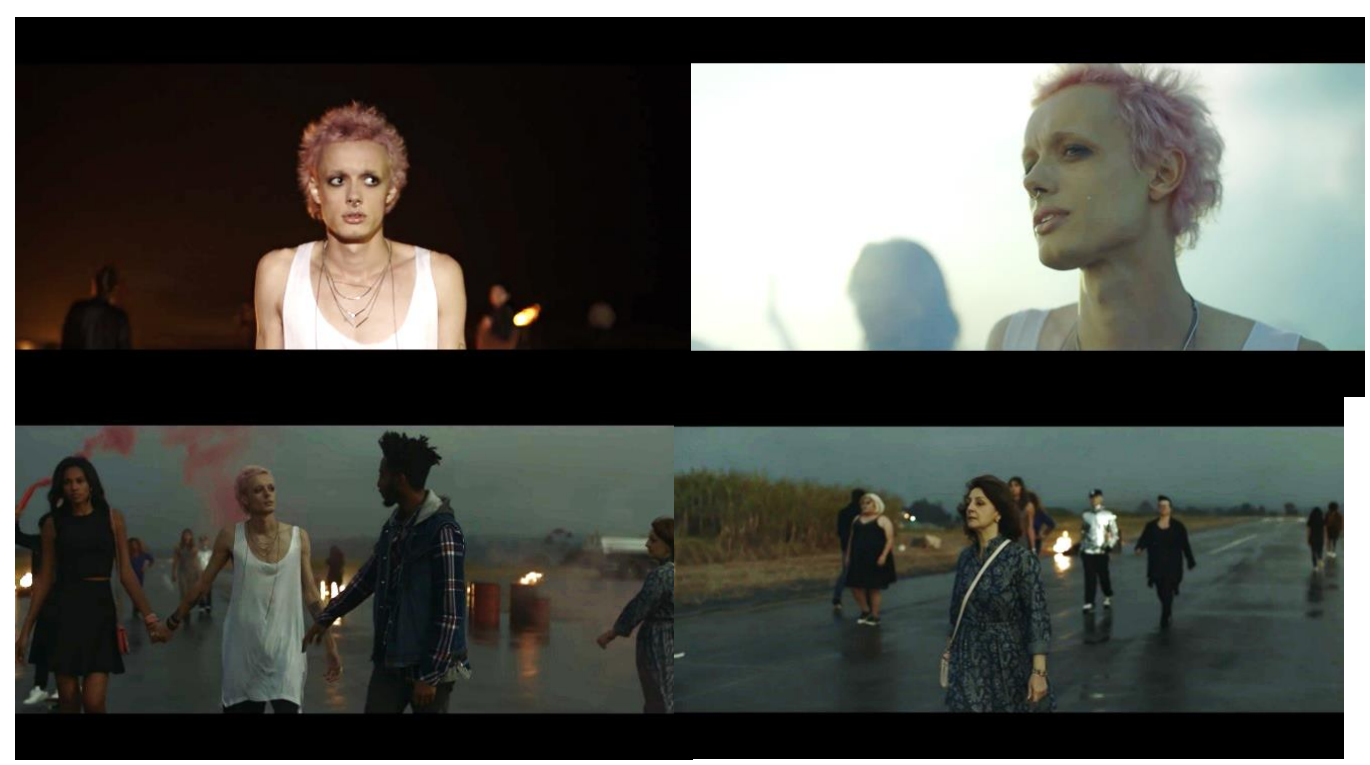

Fonte: campanha Skol. 
As representações segundo Silva (2000 apud RIBEIRO, 2010) representação vai ser sempre uma representação, mesmo o seu oposto numa hierarquia de posições e de poder. Além de legitimarem através do poder, definem a representação de grupos sociais que as produzem. É o que Ribeiro (2010) diz sobre o papel de produção subjetiva de significados, onde nas abordagens jornalísticas, no entretenimento, cobertura televisiva da parada gay, são produzidos sujeitos e suas representações. Um exemplo é a produção de personagens caricatos, com trejeitos que não condiz com a realidade. Então, o anúncio busca um retrato justificável da real pluralidade da comunidade LGBT, mas também uma realidade presente no país, pois ao analisar os dados do censo demográfico do IBGE $^{11}$ de 2010, mais da metade da população, 50,74\%, é constituída por pessoas que se consideram pardas e pretas, $47,73 \%$ são brancas, 1,09 amarelas e 0,43 indígenas; ou seja, vivemos um quadro desproporcional na produção dos corpos e significados na sociedade como um todo, e a publicidade é um reflexo dessa desigualdade (LINS; MACHADO; ESCOURA, 2016).

Se nas representações da mulher na publicidade a tendência é representá-la com delicadeza, seu modo de representação classifica Goffman (1979) de suas intenções em cena e, a posiciona em papéis relacionados aos afazeres domésticos, para atores negros - quando esses ainda estão presentes -, sempre é reservado a atividades braçais, de servidores de segunda classe, quando retratados em destaque, as representações ainda os objetificam pelos atributos físicos e os categorizam entre jogadores, músicos, dançarinos. A imagética social representada na publicidade brasileira é excludente e desigual, se a lógica de representação para se aproximar do consumidor é justamente por fator de identificação, a maioria representada são homens brancos (GASTALDO, 2013).

Um projeto de lei considerado polêmico, no 4370/98 do deputado Paulo Paim (PT/RS) ${ }^{12}$, que previa cotada de $25 \%$ nos programas televisivos e de $40 \%$ na publicidade de participação de atores negros, uma tentativa de visibilidade da população negra na mídia, representando um contingente populacional disposto sobre representações racial e étnica. Na época a Associação Brasileira de Agências de Propaganda - (ABAP) por meio do presidente alegou que a lei invadia a liberdade criativa do autor, reduziu ainda o papel da publicidade como um ato de venda e produtora de comerciais apenas e, que deveria ser avaliado como bom ou ruim pelo

\footnotetext{
${ }^{11}$ IBGE (2010) - Instituto Brasileiro de Geografia e Estatística

${ }^{12}$ Projeto de Lei 4370/98 - Câmara dos deputados. Disponível em: < http://www.camara.gov.br/proposicoesWeb/fichadetramitacao?idProposicao=20842\&ord=1 > Acessado em 25 de nov. 2016.
} 
consumidor, o projeto foi arquivado. (GASTALDO, 2011) Houve uma outra tentativa mais tarde com um outro projeto que na ementa visava políticas de valorização ética sociais, mas foi arquivado $^{13}$ junto ao primeiro.

O conservadorismo na publicidade tenta por meio do próprio discurso descaracterizar a responsabilidade sob fatores sociais que têm em seu domínio discursivo e que negligência as situações de desigualdades. Num apanhado comparativo entre os códigos de regulamentação brasileira e a do Reino Unido feitas por Gastaldo (2011), mostraram que embora o código brasileiro tenha sido criado a partir do The British Codes of Advertising and Sales Promotion, há certo despreparo e imprecisão das resoluções. Enquanto no artigo 5.1 do código britânico temos atenção para "sexo" (masculino/feminino) - embora hoje usa-se gênero - e "orientação sexual" (homo/heterossexual) - embora orientação abarque outras experiências -, no correspondente artigo 20 do brasileiro, especificação que orienta ambos os códigos a respeito de ofensas, vem resumido em termos generalistas como "discriminação social". Entende-se que essa imprecisão no reconhecimento das opressões sofridas pelas minorias endossa discursos estigmatizados, onde mulheres seminuas são retratadas como "apelo de vendas", corpo negro segue objetificado e o código não achará ofensivo.

Ao fim do anúncio nota-se que a campanha não acaba nesse momento, as pessoas estão unidas, a comunidade está unida, mas é o começo do dia e o "Respeito Is On”. Dá a entender que ao amanhecer as pessoas que fazem parte da sigla LGBT terão um lugar ao sol, não estão sozinhas, além de aproximar a marca de um público diverso, todos marcham juntos, é um dia de orgulho, e toda marcha tem um símbolo para representar o movimento, nesse caso, nada mais simbólico do que levantar a bandeira da diversidade, aquela que representa as lutas travadas a cada dia. (figura 8).

\footnotetext{
13 Projeto de Lei 2651/2000 - Câmara dos deputados. Disponível em: < http://www.camara.gov.br/proposicoesWeb/fichadetramitacao?idProposicao=18440 > Acessado em: 25 de no. 2015.
} 


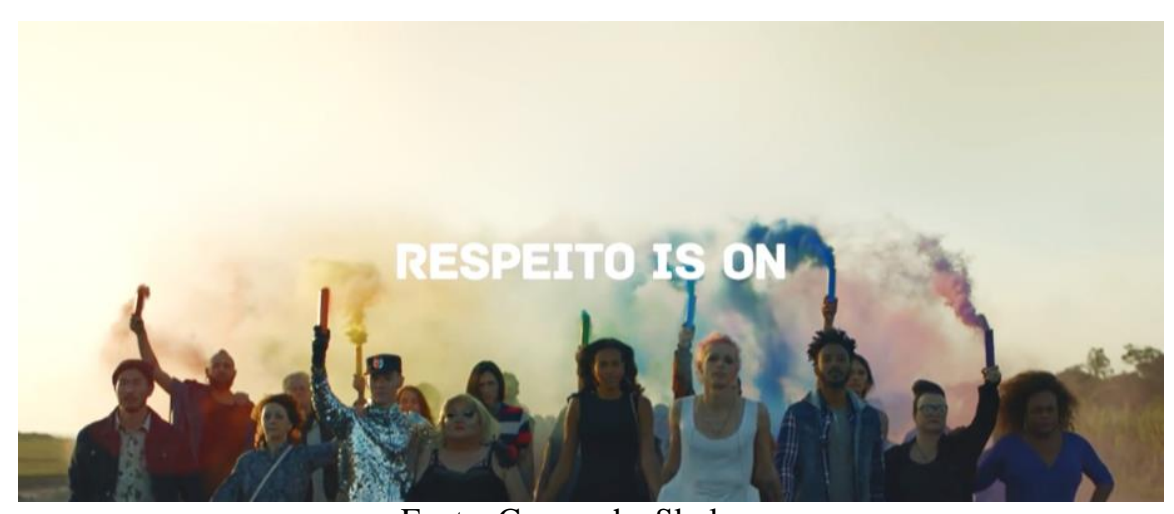

Fonte: Campanha Skol.

\section{Considerações finais}

As construções das identidades perpassam por mediações da cultura onde está inserida, tais mediações seguem um modelo dominante e de governança dos corpos sociais. Os critérios de avaliação das condutas são calcados na estrutura de poder predominante, no entanto essa estrutura não consegue apagar a existência de outras, porém é possível que ao adotar políticas de negligência as estruturas hegemônicas contribuam para subjugá-las a segundos e terceiros planos. As instituições sociais terminam por adotar o mesmo padrão conservador e hierárquico, a excludente não acontece por expulsão, mas pela invisibilidade dessas identidades.

O universo simbólico das marcas é dotado da capacidade de construir realidades ficcionais, ainda que apoiadas ao real, as marcas tendem a ser seletiva para com os aspectos retratados em campanhas. Conflituosa ideia de valores, posturas são assumidas em detrimento de outras, ainda que assuma sua consciência social o primeiro plano de uma marca é pensado para o lucro, a intenção se transforma em um polo positivo no momento em que estudos apontem para progressivos resultados, a chamada especulação. Um posicionamento não vem antes do enunciado, a mudança de perspectivas publicitárias também não. A medida que as variáveis incontroláveis são postas sobre a mesa, cabe ao mediador puxar as cadeiras para se sentarem. 


\section{Referências}

ASSUMPÇÃO, R. Homossexualidade: produção cultural, cidadania e saúde. Rio de Janeiro: ABIA, 2004.

BARTHES, R. Introdução à Análise Estrutural da Narrativa. In:. ;.TODOROV,

T; GREIMAS, A. J.; BREMOND, C.; ECO, U. GRITTI, J.; MORIN, V.; METZ,C.; GENETTE, G. Análise Estrutural da Narrativa. Rio de Janeiro: Vozes, 1977.

BELLO, M. R. L. L. Narrativa literária e narrativa fílmica: o caso de Amor de Perdição. Lisboa, 2001.

BOONE, L. E; KURTZ, D, L.A influência do consumidor nas decisões de marketing. Curitiba: Ibpex, 2012.

CARRASCOZA, J. A. Razão e sensibilidade no texto publicitário: Como são feitos os anúncios que contam histórias. 2 ed. São Paulo: Futura, 2004.

Estratégias criativas da publicidade: consumo e narrativa publicitária.

São Paulo: Estação das Letras e Cores, 2014.

FOUCAULT, M. História da sexualidade: o cuidado de si. 10. ed. Tradução de Maria Thereza da Costa Albuquerque e José Augusto Guilhon Albuquerque. Rio de Janeiro: Edições Graal, 1988.

FRIEDMAN, Norman. Point of View in Fiction. The Development of a Critical Concept Publications of the Modern Language Association of America, 1955.

GASTALDO, É. Publicidade e Sociedade: uma perspectiva antropológica. Porto Alegre: Sulina, 2013.

JODELET, D. Representações sociais: um domínio em expansão. In: As Representações sociais. Rio de Janeiro: Eduerj, 2001, p. 06-44.

LINS, B; MACHADO, R.; ESCOURA, M. Diferentes não desiguais: a questão de gênero na escola. São Paulo: Editora Reviravolta, 2016.

MOSCOVICI, S. Representações Sociais Investigações em Psicologia Social. Tradução de Pedrinho A. Guareschi. 5. ed. Petrópolis: Vozes, 2007.

NICOLAU, Marcos. Desígnios de signos: a relação entre poesia de vanguarda e publicidade impressa. 2 ed. João Pessoa: Marca de Fantasia, 2011.

PAIXÃO, Marcia Valéria. A influência do consumidor nas decisões de marketing. Curitiba: Ibpex, 2012. 
PULLAK, M. In: NUNAN, Adriana. Homossexualidade: Do preconceito aos padrões de consumo. Rio de Janeiro: Edição do autor, 2015.

SCHMID, Wolf. Narratology: an introduction. Berlin/New York: Walter de Gruyter GmbH \& Co. KG, 2010.

SEFFNER, Fernando. Composições (com) e resistências (à) norma: pensando corpo, saúde, políticas e direitos LGBT. In: COLLING, Leandro. Stonewall $40+$ o que no Brasil?. Salvador: EDUFBA, 2011.

SIMÕES, J. A.; FACCHINI, R. Na trilha do arco-íris: do movimento homossexual ao LGBT. São Paulo: Editora Perseu Abramo, 2009.

TODOROV, Tzvetan. Grammaire du Décaméron. La Haye, 1969.

VILA NOVA, Sebastião. Introdução à sociologia. 5 ed. - São Paulo: Editora Atlas, 1999. 